\title{
Left Ventricular Force-Velocity Relations Measured from Quick Volume Changes
}

\author{
Piet Schiereck and Herman B. K. Boom* \\ Laboratories of Medical Physiology and Medical Physics, State University of Utrecht, 3521 GG Utrecht, The Netherlands
}

\begin{abstract}
Left ventricles of rabbit hearts were subjected to series of quick volume releases (QVR) - taking place within $6 \mathrm{~ms}$ - applied at fixed times in the cardiac cycle. The hearts were paced artificially and allowed to contract isovolumically. The QVR was used as a tool for realizing predetermined pressure values at any time during the ascending limb of the intra-ventricular pressure curve. Any desired pressure could be attained by suitable choice of the QVR amplitude. By relating $d P / d t$ values occuring immediately after the QVR to the pressure attained by the QVR for different QVR amplitudes, instantaneous $d P / d t$ relations were obtained. Time effects on these relations were studied by repeating the QVR series with increasing amplitudes at different but constant times. Influences of volume and contractile state were examined by varying end diastolic pressure (EDP) and the perfusate $\left[\mathrm{Ca}^{2+}\right]$. The data were fitted with a $d P / d t-P$ relation derived from the Hill equation using a simple geometric model of the ventricle and a two element model of the myocardium. The experimental relations were described adequately by the model. The parameters in the Hill equation estimated for heart muscle were compared to those previously reported on heart muscle experiments. Parameter values obtained were: $a / F_{o}: 0.001-1.3 ; F_{o}$ (mean maximal force for $V_{\mathrm{CE}}=0$ ): $12.5-3.5 \mathrm{~N} ; b$ : $1.7-13.2 \mathrm{~cm} / \mathrm{s} . F_{o}$ rises at the beginning of systole and shows a plateau from ca. $60-100 \%$ time of peak pressure. This time course was influenced by changes in EDP and $\left[\mathrm{Ca}^{2+}\right]$. Parameter $b$ exhibits a time course comparable to that of ventricular pressure. It was not influenced by EDP changes and only slightly increased by an increase in $\left[\mathrm{Ca}^{2+}\right]$.
\end{abstract}

Key words: Left ventricle - Force-velocity relation Quick volume release - Active state - Hill equation - Ventricular model.

\footnotetext{
* Present address: Twente Technical University, Postbox 217, Enschede, The Netherlands
}

\section{Introduction}

A major determinant of cardiac function is the dynamic characteristic of heart muscle. It is now generally accepted that under suitably chosen conditions myocardial force-velocity relations are comparable to those of skeletal muscle [2-4, $8-12,18,21,22,24,25]$, and that a Hill-type equation applies to both. A technique that has been used to obtain force-velocity relations at constant activation and contractile element length is that of the isotonic quick release. During these releases a muscle contracts isometrically until muscle tension is suddenly released to a predetermined lower value (afterload). Thereafter the muscle is allowed to contract isotonically. The shortening velocity immediately after the release is then measured and related to the selected afterload.

There remains, however, the question how far these results apply quantitatively to the intact ventricle. It still remained to be demonstrated whether the way in which the ventricle generates pressure at various volumes (preloads) is compatible with the concept of hyperbolic tension-velocity relations for heart muscle. In the study reported here this problem has been considered in two steps. First, experiments on intact isolated rabbit ventricles were carried out which are analogous to the quick release experiments on muscle. Secondly, a relatively simple model of the ventricle was designed in which both myocardial muscle properties and geometric aspects of the ventricle were incorporated [27]. It could be shown that the time course of pressure redevelopment observed immediately after the quick volume release (QVR) was in accordance with the assumption made for the model. One of these assumptions implied the validity of a hyperbolic forcevelocity relation during myocardial contraction $[15,18,24,25]$. It is shown additionally that the various parameters of the mechanical characteristics to be used were within the range of values for heart muscle reported in the literature. 


\section{Methods}

Rapid decreases of ventricular volume were induced by a small servodriven pump. A complete experimental setup has been described elsewhere [23]. Rabbits, anesthetized with sodium pentobarbital ( $30 \mathrm{mg} / \mathrm{kg}$ body weight) were thoracotomized and the hearts excised. The hearts were connected to an apparatus enabling perfusion of the coronary system with oxygenated $\left(95 \% \mathrm{O}_{2}, 5 \% \mathrm{CO}_{2}\right)$ saline solution. Perfusion pressure was $6.7 \mathrm{kPa}$. The heart was allowed to contract isovolumically after end diastolic pressure (EDP) had been set to a controlled value prior to each beat. The heart was forced to contract at a regular low frequency by cauterizing the $\mathrm{AV}$ node and the bundle of Hiss. Electrical pacing was realized by means of rectangular pulses with a duration of $1-5 \mathrm{~ms}$. Intraventricular pressure was measured with a Millar PC $350 \mathrm{~A}$ catheter tip manometer introduced into the ventricle via a small hole in the ventricular wall near the apex [23].

Quick volume decreases were effected by way of a cannula tied into the mitral orifice [23]. Quick releases with successively increasing amplitude were effected at a constant point in time in 20 subsequent contractions. In classical quick release experiments, contraction following the quick release was isotonic in order to assess shortening velocity. In the ventricle true isotonic contractions are very difficult to realise. Therefore, immediately following a quick release the ventricle was again forced to contract isovolumincally and shortening velocity derived indirectly from the value of $d P / d t$ found at that instant. After the release, the developed pressure and rate of pressure development were related to each other for different magnitudes of the volume steps. This yieided relationships to myocardial force-velocity curves measured at a fixed time and therefore at a fixed level of myocardial activation. The implicite assumption when using this method is that the level of activation is not affected by the quick volume release (QVR) $[9,11]$.

The $d P / d t-P$ relations obtained from the (QVR) experiments were compared with myocardial force-velocity relations. For this the experimental $d P / d t-P$ relations were fitted with a theoretical $d P / d t-$ $P$ relation derived from myocardial force-velocity data, using a simplified geometrical model of the left ventricle. The muscle in the wall was described by the Hill two element model in which an active contractile element (CE) obeying a hyperbolic force-velocity relation $[15,18,24,25]$ is connected in series with a passive elastic element (SE) with an exponential force-extension characteristic $[15,26,30]$ according to:

$d F / d l_{\mathrm{SE}}=k(F+R)$

where $l_{\mathrm{SE}}$ is the length of the SE and $k$ and $R$ are constants. Because of the fact that the CE was assumed to be highly damped, a change of the length of the muscle induced by a quick release was equal to the change of the length of the SE. Under isotonic conditions shortening velocity of the $\mathrm{CE}, \mathrm{V}_{\mathrm{CE}}$, is related to the force of the $\mathrm{CE}$ by the Hill Eq. [9,24]:

$\left(V_{\mathrm{CE}}+b\right)(F+a)=b\left(F_{0}+a\right)$

where $-V_{\mathrm{CE}}$ is CE shortening velocity and $a, b$ and $F_{0}$ are constants. Parameters $a$ and $b$ are proportional to muscle cross sectional area and muscle length, respectively. This equation is in remarkable agreement with velocity data of isotonically contracting skeletal muscle [16] and heart muscle [13]. It has been shown that Eq. (2) is also valid for the case of non-isotonically (i.e. approximately isometrically) contracting muscle, as in the present study [8-10,21]. Note that for $V_{C E}=0: F=F_{0}$.

During isometric contraction shortening velocity of the $\mathrm{CE}$ is related to the rate of force development by:

$d F / d t=d F / d l_{\mathrm{SE}} \cdot d l_{\mathrm{SE}} / d t=d F / d l_{\mathrm{SE}} \cdot V_{\mathrm{CE}}$.

Combining (1), (2) and (3) rate of force development before and after the QVR is found from:

$d F / d t=B(F+R)\left(F_{0}-F\right) /(a+F)$ where $B=b k$. For a number of possibly usable reference shapes for the left ventricle the relation between total circumferential wall force $F$ and intra-cavital pressure $P$ can be represented by:

$P=F / L$

where $L$ is a general proportionality constant, equal to the total cross sectional surface area upon which $P$ is supposed to act. In fact the actual form of $L$ depends on the kind of geometry used. For the simple case of the thin walled sphere Laplace's law is obtained since then $L=\pi r^{2}$. Although later on this particular case will be applied, it is at present unnecessary to specialize to this extent. The advantage of this procedure is that up to the moment at which the actual geometry will be used, results are unaffected by this choice. The only condition here is that $F$ may be assumed to be evenly distribution over the left ventricular wall [5]. Substitution of Eq. (5) in Eq. (4) yields a relation between ventricular pressure $P$ and rate of ventricular pressure development $d P / d t$ :

$d P / d t=B\left(P+R^{\prime}\right) \cdot\left(P_{0}-P\right) /\left(a^{\prime}+P\right)$.

Where $a^{\prime}$ and $R^{\prime}$ are normalized values of $a$ and $R$

$a^{\prime}=a / L ; R^{\prime}=R / L$.

Eq. (6) was used for fitting the experimental $d P / d t-P$ relations.

\section{Results}

With the technique described, ventricular $d P / d t-P$ relations could be obtained at any moment during the cardiac cycle. In the present study results were obtained mainly during the ascending limb of the systolic phase, or, in a few cases, during the early part of relaxation. In total 40 hearts were examined.

In Fig. 1 a values of $d P / d t$ occuring immediately after a quick volume decrease $\Delta V$ are plotted as a function of $P$ at the same instant. Volume decreases had progressively increasing amplitudes and were effected each at $t_{\mathrm{QR}} \mathrm{ms}$ after stimulation during subsequent beats. Figure 1 a shows a $P$ value after $\Delta V=0$ which equals $14 \mathrm{kPa}$. After the $17 \mathrm{th}$ volume step $P$ was reduced to $2.5 \mathrm{kPa}$ while $d P / d t$ was increased to $0.27 \mathrm{kPa} / \mathrm{ms}$. In Fig. $1 \mathrm{~b}$ and $\mathrm{c}$, however, the $d P / d t-P$ relation is dome-shaped, a fact encountered in most of the experiments, although a number of them are of the type of Fig. 1 a. In those cases where the maximum in the $d P / d t-P$ curve was attained at low $P$ values, or was not observed at all, an appreciable part of the $d P / d t-P$ curve was linear. Note that the relations as shown in Fig. 1 did not reach the $P$-axis at the right side, since $\Delta V$ $=0$ (the undisturbed pressure curve) in general implies $d P / d t \neq 0$, except in the top of the pressure-time curve.

In the following, interpretation of $d P / d t-P$ curves will be undertaken with the help of the $d P / d t-P$ relation [Eq. (6)]. It was used for fitting (least squares approximation) the experimental data yielding a set of parameters. These described the mechanical and contractile properties of the ventricular myocardium under the existing conditions as to time, preload and inotropic state. 

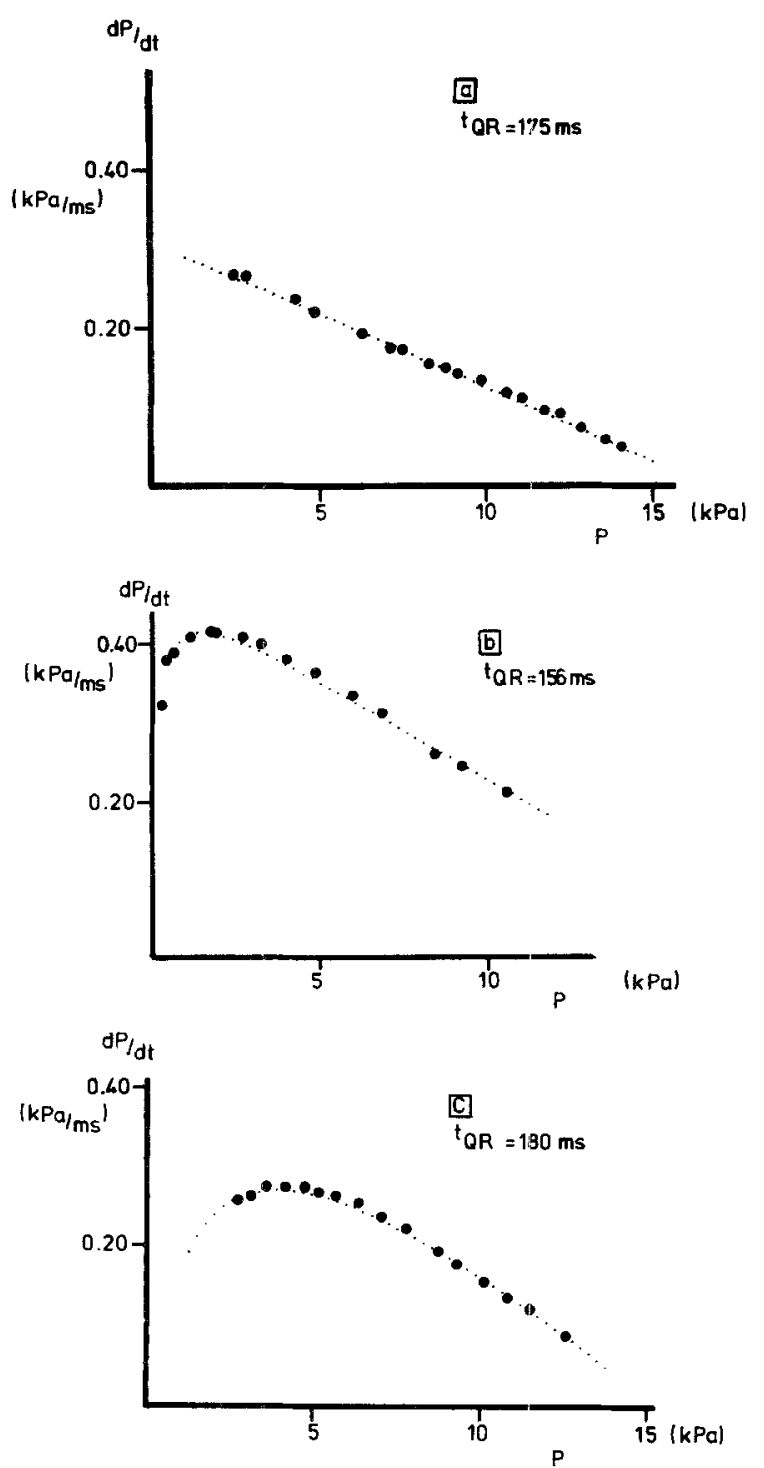

Fig. 1 a-c. $d P / d t-P$ relations obtained from series of increasing quick volume releases at a particular time during systole. The filled circles represent the experimental data. $d P / d t$ and $P$ values were measured immediately following a ventricular quick volume release and were varied by changing the magnitude of the release. Various types of curves were obtained: a linear $d P / d t-P$ relation, b relation with a maximal $d P / d t$ at low $P$ value, $\mathrm{c}$ relation with a maximal $d P / d t$ at moderate $P$ value. Dotted lines: theoretical relation obtained by fitting Eq. (6). Values of the fitted muscle parameters are

\begin{tabular}{lllllr}
\hline Fig. & $P\left(P_{\max }\right)$ & $a / F_{0}$ & $R^{\prime}$ & $B$ & $F_{0}$ \\
\hline & $\mathrm{kPa}$ & - & $\mathrm{N} \mathrm{m}^{-2}$ & $\mathrm{~s}^{-1}$ & \multicolumn{1}{c}{$N$} \\
$1 \mathrm{a}$ & 0.3 & 0.01 & 0.09 & 19 & 9.0 \\
$1 \mathrm{~b}$ & 1.6 & 0.05 & 0.09 & 26 & 10.1 \\
$1 \mathrm{c}$ & 4.0 & 0.72 & 0.05 & 36 & 8.3 \\
\hline
\end{tabular}

It was always possible to obtain a satisfactory fit between the experimental results as exemplified by Fig. $1 \mathrm{a}, \mathrm{c}$ and those as represented by Eq. (6). In cases where $a^{\prime}<<P$ and $R^{\prime}<<P$ (large $P$ values) Eq. (6) reduced to: $d P / d t=b \cdot k \cdot\left(P_{0}-P\right)$ which is the linear relationship seen in Fig. 1 a. Its slope is thus identified with $k \cdot b$. If on the other hand, while $R^{\prime}<<P, P$ has been reduced to more moderate levels, Eq. (6) can be written as: $d P / d t=k \cdot b \cdot\left(P_{0}-P\right) /\left(l+a^{\prime} / P\right)$ which shows that, for decreasing $P$, the denominator will increase, leading to a deviation of the above linear relation. A maximum will occur since at still lower values of $P$ this quantity can be neglected as compared to $P$ in the numerator. This leaves the denominator to increase further and $d P / d t$ to decrease. The maximum of $d P / d t$ occurs at $P=-a+\sqrt{a^{2}-a P_{0}}$. The dotted lines in Fig. 1 show the result of the fitting procedure for those particular examples. Note the good agreement. Although the general good fit is no proof that the model used is correct, it indicates that it describes the experimental results adequately.

The values of the fitted parameters - $a / F_{0}$ $\left(=a^{\prime} / P_{0}\right), R^{\prime}, P_{0}, \mathrm{~B}-$ found for each plot are shown in the legends of Fig. 1. Note that in Fig. $1 \mathrm{a}$ and $\mathrm{b}$ a low value of $a / F_{0}$ (relative to unity) was found. This was generally the case for those experimental curves that had a maximum at a low value of $P$, but $a / F_{0}$ was greater in the curve of Fig. $1 \mathrm{c}$. Thus the values of $a / F_{0}$ showed a large variance $(0.001-1.3)$. This is not in disagreement with the current knowledge about this parameter in papillary muscle physiology. Various values have been reported e.g. Edman [8]: 0.3-1.1; Brutsaert [2,3]: 0.07-0.34; Noble et al. [22]: 0.254.25. The results for $R^{\prime}$ found by the fitting procedure for the curves with a detectable maximum in $d P / d t$ varied between 0.02 and $0.4 \mathrm{kPa}$; data obtained from the literature are: Yeatman [30]: $0-6 \mathrm{kPa}$; Parmley [18]: $7 \mathrm{kPa}$.

The parameter $B$ was obtained with a higher degree of reproducibility for each experiment. It was shown above that for $a^{\prime}<<P$ and $R^{\prime}<<P, B$, is approximately equal to the slope of the $d P / d t-P$ relation. In general, this slope cannot be found by a simple tangent since the above conditions are not always sufficiently met. Instead, the parameter $B$ was likewise found from the fitting procedure $\left(7-49 \mathrm{~s}^{-1}\right)$.

The parameter $F_{0}\left(=P_{0} \cdot L\right)$ is of considerable physiological interest. It represents the total myocardial wall force at zero $\mathrm{CE}$ shortening velocity and has been considered as a suitable measure of muscle activation [15] both with regard to its time course as to its dependency on contractile state $[2,9,12] . P_{0}$ was found as a result of the curve fitting procedure which in this respect acted as an extrapolation technique. In order to calculate $F_{0}$ from $P_{0}$ actual ventricular geometry must be taken into account by specifying $L$. In the following, it is assumed that a spherical shape applies for the ventricle i.e. $L=\pi r^{2}$. Results will be given in terms of $F_{0}$. 

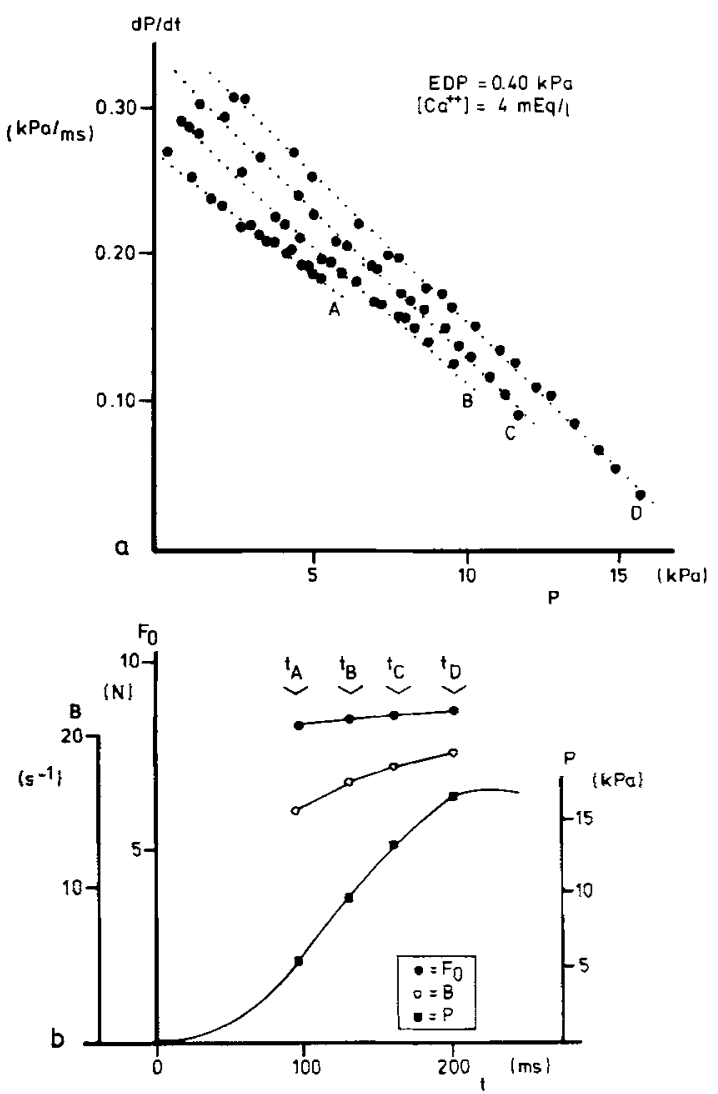

Fig. 2a. $d P / d t-P$ relations at different moments in systole. Filled circles: the experimental data; dotted lines: theoretical relations [Eq. (6)]. Fitted parameters:

\begin{tabular}{lclllll}
\hline & $t_{\mathrm{QR}}$ & $P\left(P_{\text {max }}\right)$ & $a / F_{0}$ & $R^{\prime}$ & $B$ & $F_{0}$ \\
\hline & $\mathrm{ms}$ & $\mathrm{kPa}$ & - & $\mathrm{N} \mathrm{m}^{-2}$ & $\mathrm{~s}^{-1}$ & $N$ \\
$\mathrm{~A}$ & 92 & 0.3 & 0.009 & 0.09 & 15 & 8.3 \\
$\mathrm{~B}$ & 137 & 0.3 & 0.006 & 0.14 & 17 & 8.5 \\
$\mathrm{C}$ & 164 & 0.3 & 0.007 & 0.11 & 18 & 8.6 \\
$\mathrm{D}$ & 203 & 0.3 & 0.010 & 0.13 & 19 & 8.7 \\
\hline
\end{tabular}

b $F_{0}$ and $B$ versus time of QVR corresponding to the $d P / d t-P$ relations of $a$. Drawn line represents the undisturbed pressure-time curve. QVR's as shown in a. Maximal pressure was $17 . \mathrm{kPa}$, reached at $t_{\mathrm{QR}}=220 \mathrm{~ms}$

The influence of time of applied QVR, of EDP and of inotropic state $\left(\mathrm{Ca}^{2+}\right.$ content of the perfusion fluid) on $F_{0}$ and $B$ was systematically examined. Families of $d P / d t-P$ relations were constructed (Fig. 2a) by varying the time at which the QVR was applied. After an initial rise the effect of time on $F_{0}$ levels off. This indicates a plateau in the development of myocardial "activation". This plateau was essentially found in all experiments under all conditions of EDP and inotropic state. An influence of time on $B$ to the effect that $B$ increased in time was observed. This is also shown by Fig. 2a since the asymptotic slopes are visibly different.
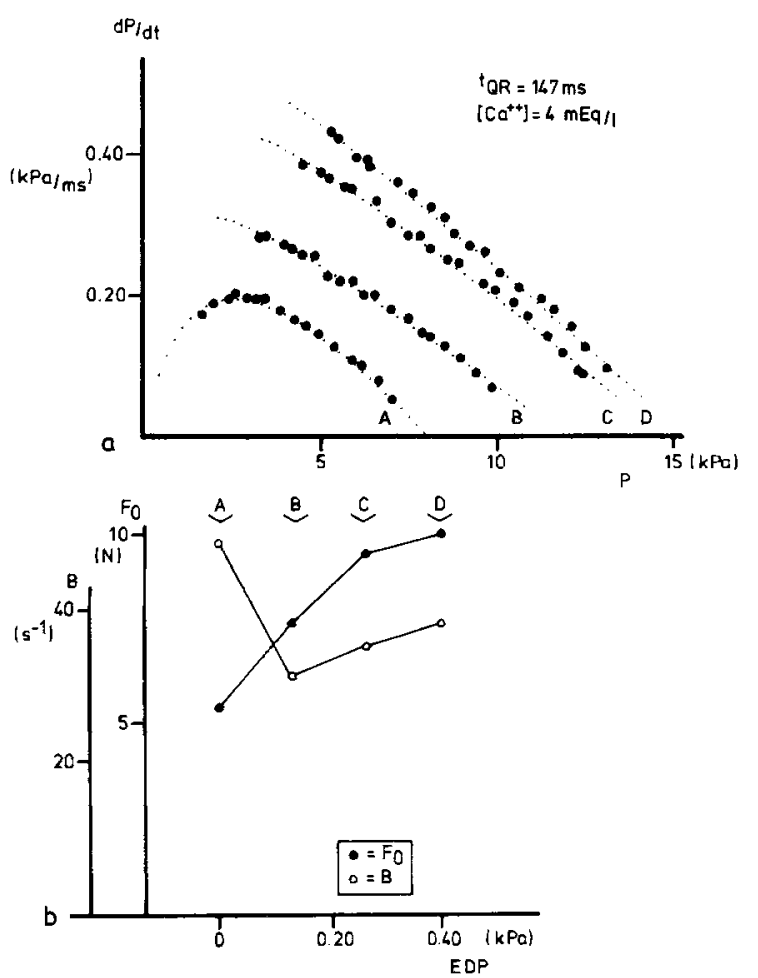

Fig. 3a. $d P / d t-P$ relations at the same time but different EDP values. Filled circles: experimental data; dotted lines: fitted results. The maximal volume change was the same for each EDP, causing a larger percentage of volume decrease at lower EDP. Fitted parameters:

\begin{tabular}{lllllll}
\hline & $\mathrm{EDP}$ & $P\left(P_{\text {max }}\right)$ & $a^{\prime} F_{0}$ & $R^{\prime}$ & $B$ & $F_{0}$ \\
\hline & $\mathrm{kPa}$ & $\mathrm{kPa}$ & - & $\mathrm{N} \mathrm{m}^{-2}$ & $\mathrm{~s}^{-1}$ & \multicolumn{1}{l}{$N$} \\
$\mathrm{D}$ & 0.40 & 2.4 & 0.12 & 0.10 & 38 & 10.0 \\
$\mathrm{C}$ & 0.27 & 2.8 & 0.19 & 0.09 & 35 & 9.5 \\
$\mathrm{~B}$ & 0.13 & 2.3 & 0.19 & 0.09 & 31 & 7.7 \\
$\mathrm{~A}$ & 0 & 3.2 & 1.34 & 0.05 & 49 & 5.4 \\
\hline
\end{tabular}

b $F_{0}$ and $B$ corresponding to Fig. 3 a plotted versus EDP. The high $B$ value at low EDP was not found systematically in all experiments. (See also Fig. 5b)

The dependency of $F_{0}$ and $B$ on end diastolic pressure is shown in Fig. 3 . As could be expected, $F_{0}$ increases with increasing EDP, representing the classical Starling mechanism. On the other hand, no systematic effect of EDP on $B$ could be detected.

Changes in the inotropic state of the ventricle were brought about by modifying the extracellular $\left[\mathrm{Ca}^{2+}\right]$. Figure 4 demonstrates the effects of three $\left[\mathrm{Ca}^{2+}\right]$ levels on the $d P / d t-P$ relations and the associated parameter values. $F_{0}$ was not only affected by EDP but, as is to be expected, by the inotropic state also. In this case there was no effect of inotropic changes on $B$. 

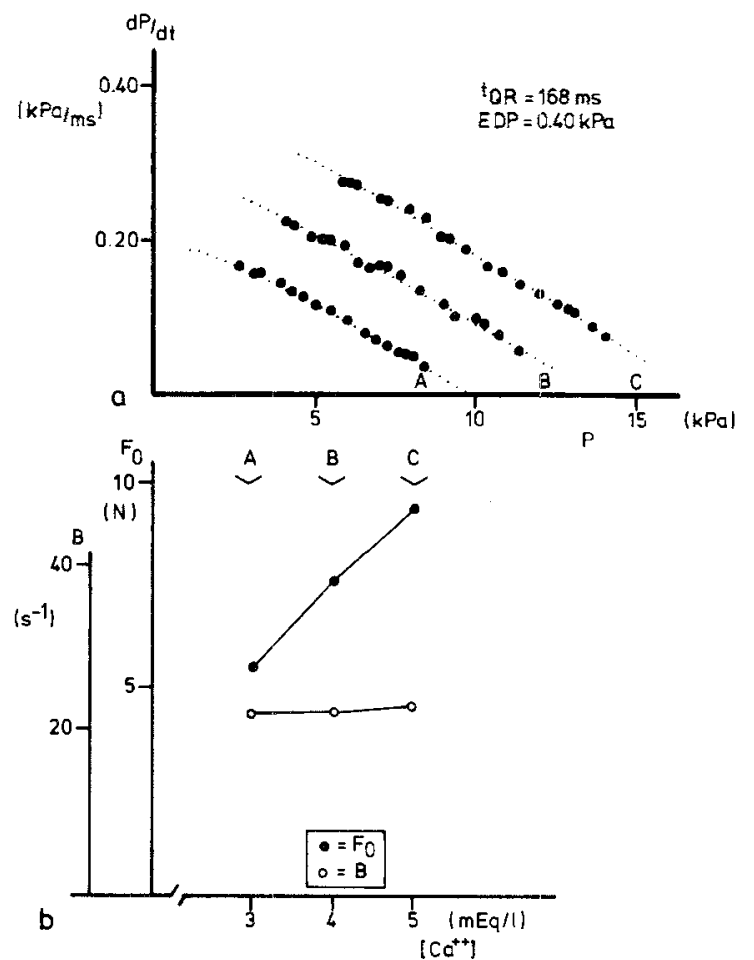

Fig. 4a. $d P / d t-P$ relations at one time and one EDP value but three different values of perfusate $\left[\mathrm{Ca}^{2+}\right]$. Filled circles: experimental data; dotted lines: fitted results. Fitted parameters:

\begin{tabular}{lllllll}
\hline & {$\left[\mathrm{Ca}^{2+}\right]$} & $P\left(P_{\text {max }}\right)$ & alF & $R^{\prime}$ & $B$ & $F_{0}$ \\
\hline & $\mathrm{mEq} \cdot 1^{-1}$ & $\mathrm{kPa}$ & - & $\mathrm{N} \mathrm{m}^{-2}$ & $\mathrm{~s}^{-1}$ & $N$ \\
$\mathrm{C}$ & 5 & 1.3 & 0.08 & 0.10 & 25 & 9.4 \\
$\mathrm{~B}$ & 4 & 1.2 & 0.05 & 0.10 & 24 & 7.6 \\
$\mathrm{~A}$ & 3 & 1.8 & 0.11 & 0.10 & 24 & 5.5 \\
\hline
\end{tabular}

b $F_{0}$ and $B$ as a function of the $\left[\mathrm{Ca}^{2+}\right]$ from the $d P / d t-P$ relations shown in Fig. 4a
Time courses of the parameters $F_{0}$ and $B$ during the first part of ventricular systole resulting from changes in EDP are depicted in Fig. 5 and 6. In these figures average values summarizing all experiments are presented. Figure 5 a shows normalized time courses of $F_{0}$ $\left(t^{\prime}\right)$ for four EDP values ( $t^{\prime}$ applies to normalized time). There is a clear cut influence of EDP on $F_{0}\left(t^{\prime}\right)$. Also it is clear that from EDP $=0.27-0.40 \mathrm{kPa}$ the increase in $F$ is only slight, indicating the vicinity of the peak of the Frank-Starling curve. A plateau is manifest at all EDP values, beginning at about $0.6 t_{P_{\max }}$. In the upstroke and in the downstroke of these $F_{0}$ curves, $d F_{0} / d t$ seems to be very little influenced by EDP.

While an increase of EDP results in an upward shift of the $F_{0}$ curve, this effect is far less clear for $B$ (Fig. 5b), although there is an increase in $B$ with time. In none of the experimental material presented in this study could a significant influence of EDP on the time course of the parameter $B$ be detected.

In an analogous way the effect of the inotropic state on the time course of the normalized parameter $F_{0}$ was studied. Figure 6 a shows the result for one EDP value $(0.40 \mathrm{kPa})$. The influence of changes of inotropic state is clearly visible. The three curves were constructed from 24,24 and 15 experiments respectively. The plateau is shifted upwards as a result of an increase of $\left[\mathrm{Ca}^{2+}\right]$. A slight but still significant $(P<0.01)$ effect of $\left[\mathrm{Ca}^{2+}\right]$ is visible on the time course of $B$. In Fig. $6 \mathrm{~b}$ the corresponding curves are reproduced for the lowest and highest values of $\left[\mathrm{Ca}^{2+}\right]$.

The numerial values of $F_{0}$ and $B$ found in this study for $t=0.8 \times t_{P_{\max }}$ together with their standard deviation are presented in Tables 1 and 2 . As can be seen from the standard deviation, the variability of the numerical
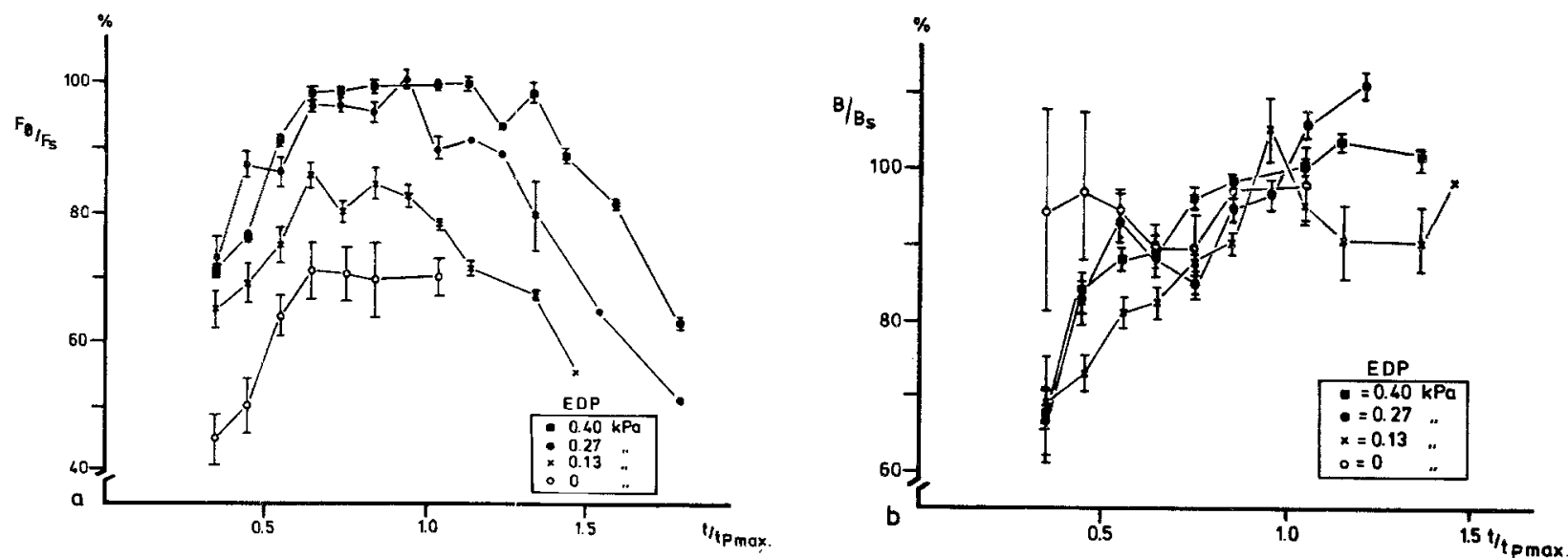

Fig. 5a. Normalized time course of averaged normalized $F_{0}$ values as found from the complete series of experiments. Each value of $F_{0} / F_{s}$ is found as the average of values within a class of one tenth of the $t_{P_{\text {max }}}$ of the experiments. $F_{s}$ represents the $F_{0}$ value corresponding to $t_{P}$ and EDP $=0.4 \mathrm{kPa}$ of each experiment. Total number of experiments for EDP: 27, 20,13 and 7 for EDP values $0.40,0.27,0.13$ and $0 \mathrm{kPa}$ resp. Note the plateau reached for each EDP at about $0.6 \times t_{P_{\max }}$. At higher EDP the plateau is of higher duration, suggesting a prolonged "active state". b Time course of $B$, normalized by dividing by $B_{s}$ (The value reached at $t_{P_{\max }}$ and $\mathrm{EDP}=0.40 \mathrm{kPa}$.) $B / B_{s}$ reaches its maximum at the same time as pressure. Vertical bars represent the SEM of the calculated mean values of $B / B_{s}$ 

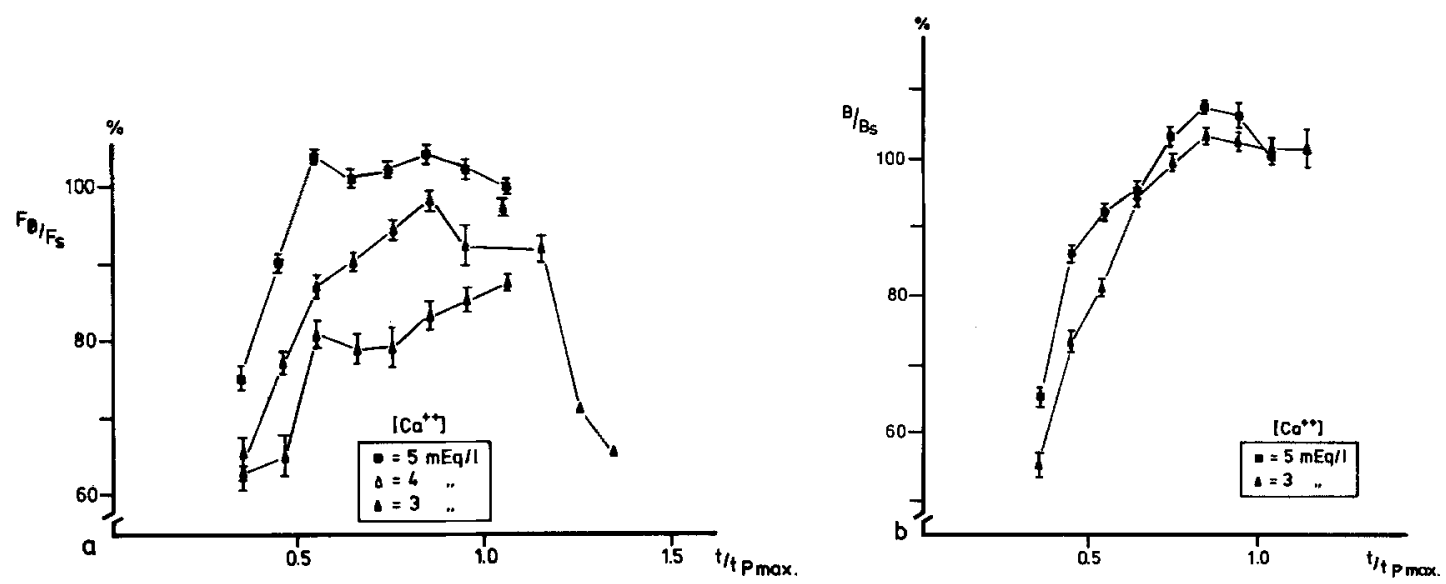

Fig. 6a. The influence of $\left[\mathrm{Ca}^{2+}\right]$ on the time course of normalized $F_{0}$. Here $F_{s}$ represents $F_{0}$ value at $\mathrm{EDP}=0.40 \mathrm{kPa}$ and highest $\left[\mathrm{Ca}{ }^{2+}\right]$ value at $t_{P}$. This figure is constructed in the same way as Fig. 5. Total number of experiments: from high to low $\left[\mathrm{Ca}^{2+}\right]: 24,24$, and 15 . Vertical bars represent the SEM of the calculated mean values. $\mathbf{b}$ The influence of $\left[\mathrm{Ca}^{2+}\right]$ on the time course of normalized $B$. Highest and lowest $\left[\mathrm{Ca}^{2+}\right]$ values are shown. The same series of experiments as in Fig. 6 a are depicted. A slight effect of $\left[\mathrm{Ca}^{2+}\right]$ is visible. Vertical bars represent the SEM of the calculated mean values

Tables 1 and 2. Numerical data of $F_{0}$ and $b$ found for one particular time in systole $\left(0.8 \times t_{P_{\max }}\right)$ for $\left[\mathrm{Ca}^{2+}\right]$ and EDP variations to be used for comparison with heart muscle data

Table 1. $F_{0}[\mathrm{~N}] \quad t=0.8 \times t\left(P_{\max }\right)$

\begin{tabular}{|c|c|c|c|c|}
\hline $\begin{array}{l}{\left[\mathrm{Ca}^{2+}\right]} \\
\mathrm{mEq} / 1\end{array}$ & $\begin{array}{rl}\mathrm{EDP} & 0 \\
\mathrm{kPa} & \end{array}$ & 0.13 & 0.27 & 0.40 \\
\hline 5 & $\begin{array}{l}5.9 \\
\text { SD: } 2.4\end{array}$ & $\begin{array}{l}7.2 \\
\text { SD: } 2.4\end{array}$ & $\begin{array}{l}8.5 \\
\text { SD: } 2.1\end{array}$ & $\begin{array}{l}9.8 \\
\text { SD: } 0.9\end{array}$ \\
\hline 4 & $\begin{array}{l}6.3 \\
\text { SD }: 1.8\end{array}$ & $\begin{array}{l}7.0 \\
\text { SD: } 0.9\end{array}$ & $\begin{array}{l}8.0 \\
\text { SD: } 0.9\end{array}$ & $\begin{array}{l}8.7 \\
\text { SD: } 1.0\end{array}$ \\
\hline 3 & - & - & - & $\begin{array}{l}7.0 \\
\text { SD }: 1.9\end{array}$ \\
\hline
\end{tabular}

Table 2. $b^{\prime}\left[\mathrm{s}^{-1}\right] \quad t=0.8 \times t\left(P_{\max }\right)$

\begin{tabular}{|c|c|c|c|c|}
\hline $\begin{array}{l}{\left[\mathrm{Ca}^{2+}\right]} \\
\mathrm{mEq} / 1\end{array}$ & $\begin{array}{rl}\mathrm{EDP} & 0 \\
\mathrm{kPa} & \end{array}$ & 0.13 & 0.27 & 0.40 \\
\hline 5 & $\begin{array}{l}0.90 \\
\text { SD: } 0.85\end{array}$ & $\begin{array}{l}0.90 \\
\text { SD: } 0.14\end{array}$ & $\begin{array}{l}1.04 \\
\text { SD: } 0.14\end{array}$ & $\begin{array}{l}1.08 \\
\text { SD: } 0.14\end{array}$ \\
\hline 4 & $\begin{array}{l}0.95 \\
\text { SD: } 0.19\end{array}$ & $\begin{array}{l}0.90 \\
\text { SD: } 0.12\end{array}$ & $\begin{array}{l}0.94 \\
\text { SD: } 0.12\end{array}$ & $\begin{array}{l}1.04 \\
\text { SD: } 0.13\end{array}$ \\
\hline 3 & - & - & - & $\begin{array}{l}0.99 \\
\text { SD: } 0.16\end{array}$ \\
\hline
\end{tabular}

values was appreciable, due to individual differences in the preparation etc. as mentioned before.

To compare this $F_{0}$ with values of maximal tension obtained from papillary muscle experiments as presented in the literature, the cross sectional area of the myocardial wall of the ventricle has to be taken into account. Under the assumption of spherical geometry of the ventricle, this area equals $\pi\left(r_{0}^{2}-r_{i}^{2}\right)$, where $r_{0}$ and $r_{i}$ are the outer and inner radii of the sphere respectively. Values of $r_{0}$ and $r_{i}$ may be estimated from average figures of ventricular volume $V_{i}\left(2 \mathrm{~cm}^{3}\right)$ and myocardial weight $V_{w}(7.5 \mathrm{~g})$. Thus $r_{i}=\left(\frac{3}{4 \pi} \cdot 2 V_{i}\right)^{1 / 3}=$ $1.0 \mathrm{~cm}$ and $r_{0}=\left[\frac{3}{4 \pi} \cdot 2\left(V_{i}+V_{w}\right)\right]^{1 / 3}=1.6 \mathrm{~cm}$. This corresponds to a cross section of $4.9 \mathrm{~cm}$. Myocardial wall tension calculated in this way amounted to: (21 $\pm 2)$ to $(13 \pm 4) \cdot 10^{3} \mathrm{~N} \mathrm{~m}^{-2}$. The values reported in the literature are: Edman and Nilsson [10]: 9 to $49 \cdot 10^{3} \mathrm{~N}$ $\mathrm{m}^{-2}$; Brutsaert [2]: 71 to $180 \cdot 10^{3} \mathrm{~N} \mathrm{~m}^{-2}$; Sonnenblick [25]: 6 to $42 \cdot 10^{3} \mathrm{~N} \mathrm{~m}^{-2}$; Forman [12]: $66 \cdot 10^{3} \mathrm{~N} \mathrm{~m}^{-2}$.

A comparison of the $B$ data with those in the literature is more difficult, since the $k$ must be known. Such values have been assessed frequently $[2,9,25]$, but they are under discussion and now attributed to the compliant necrotic endings of the papillary muscle preparations used in those studies. The value of $k$ may, however, be estimated from the experiments of the present study [23]. Eq. (1) may be transformed into an expression relating $d P / d V$ to $P$. Using spherical geometry:

$d P / d V \cdot 3 \cdot\left(V^{2} / 6 \pi^{2}\right)^{1 / 3}=k\left(P+R / \pi r^{2}\right)$

which is readily verified by realizing that a QVR change of the ventricular circumference $d l_{\mathrm{SE}}$ equals

$d l_{\mathrm{SE}}=d\left(6 \pi^{2} V\right)^{1 / 3}=\left(6 \pi^{2}\right)^{1 / 3} \cdot 1 / 3 \cdot V^{-2 / 3} \cdot d V$

which, introduced into Eq. (1) and after using (5) gives rise to Eq. (7). At a pre release pressure of about $13.3 \mathrm{kPa}(100 \mathrm{~mm} \mathrm{Hg})$ a quick release volume decrease 
of $\pm 0.2 \mathrm{~cm}^{3}$ results in a pressure drop to about $0 \mathrm{kPa}$ (ventricular volume $\pm 1 \mathrm{~cm}^{3}$ ). Thuis

\section{$3 \cdot(13.3 / 0.2) \cdot\left(1 / 6 \pi^{2}\right)^{1 / 3}=k(13.3)$}

where $R / \pi r^{2}$ has been taken equal to 0.6 and neglected further. This results in $k=3.8 \mathrm{~cm}^{-1}$, corresponding with a 10 fold stiffness as compared with papillary muscle literature $[3,5,10]$.

Values of $b$ are mostly given in length normalized form: $b / l=b^{\prime}$ where $l$ denotes muscle length. Therefore in Eq. (6) a value of $b=b^{\prime} \cdot 2 \pi r$ can be introduced. Thus

$B=b^{\prime} \cdot k \cdot 2 \pi r$.

Values of $b^{\prime}$ found in the literature are: Sonnenblick [24]: $0.79 \mathrm{~s}^{-1}$, Edman and Nilsson [9]: $0.59-2.19 \mathrm{~s}^{-1}$, [10]: $1.65-3.65 \mathrm{~s}^{-1}$, [11] $1.57-1.68 \mathrm{~s}^{-1}$; Noble et al. [22]: $0.44-3.84 \mathrm{~s}^{-1}$; Brutsaert et al. [2]: $0.17-$ $0.38 \mathrm{~s}^{-1}$. The lowest and highest value of $B$ as found in this study were 7 and $49 \mathrm{~s}^{-1}$ respectively. If this is substituted into Eq. (8) and using $k=3.8 \mathrm{~cm}^{-1}$ the result is $b^{\prime}=0.22 \mathrm{~s}^{-1}$ and $1.61 \mathrm{~s}^{-1}$ respectively. This is within the limits set by the former figures obtained from the literature.

\section{Discussion}

Cardiac mechanics have been developed in the following two major ways. One consisted of an extensive search into dynamic properties of heart muscle (papillary muscle). Results were presented in the form of relationships between tension, length, shortening velocity etc. under various conditions $[2-4,8-12,21$, $22,24,25]$. In the second way the intact heart was examined and mechanical interrelationships were found between cardiac variables like pressure, volume and flow etc. $[6,7,14,19,20,29]$. Relatively few investigators, however, have dealt with a direct comparison of cardiac muscle mechanics with intact heart physiologic knowledge $[1,27]$. One way to do so consists of the discription of certain ventricular phenomena in terms of muscular parameters and relations by means of a postulated model of the heart and its muscular wall [1]. The objective then has to be the demonstration that such theoretical predictions, using known numerical muscle data, are compatible with observed facts on intact heart behaviour. It is then of appreciable advantage to use experimental techniques like the ventricular quick release method that are analogous of those employed for obtaining the basal muscle data to which the model was fitted.

A complication of the ventricular quick release is formed by the fact that after quick release no real isotonic contraction can be reached. After release contraction velocities have therefore to be derived indirectly from e.g. $d P / d t$ data. This necessitates knowledge about the essential link between tension and length of the muscle: elasticity. This can, however, be derived from the ventricular quick release itself as reported by Schiereck and Boom [23]. The main issue of the investigation reported here consists in ascertaining that the quick release response of the ventricle is quantitatively compatible with the hypothesis of a hyperbolic force-velocity relation valid within its muscular wall. Evidence for this can be summarized as follows: 1. The model Eq. (6) fits the experimental data in virtually all cases with a high degree of accurary. 2. There is no discrepancy between the parameter values found from the model fitting procedure and those from papillary muscle literature. The large variance observed in $a / F_{0}$ is reflected in a consonant dispersal of results among a number of authors (see Introduction), which suggests that this parameter indeed is extremely sensible for the measuring method.

Of special interest is the constructed time course of the parameter $F_{0}$. In the present study it was found that at least during an interval prceding $t_{P_{\max }}, F_{0}$ varied little, suggesting that myocardial activation as expressed by $F_{0}$ also was more or less constant. This is in agreement with the findings reported by Joseph and Huntsman $[17]$ and may be compared with the findings $[3,4]$ that for a significant period during papillary muscle contraction the relation between tension, velocity and length was unaltered. The plateau phenomenon found could be subjected to the criticism that it is a rather indirect result depending on the validity of the model used. However, the physiological meaning of $F_{0}$ goes beyond the detailed structure of the force-velocity hypothesis. Any model allowing for the fact that tension is maximal at zero contraction velocity would yield similar results. As such the derivation of $F_{0}$ essentially constitutes an extrapolation of $d p / d t-P$ relations as in Fig. 1 towards the $P$-axis. Finally it has been demonstrated that muscle fibres contracting at constant sarcomere length generate force, the time course of which includes an appreciable constant part: a direct demonstration of constant $F_{0}$ [28].

Values of mean maximal force found in this study generally were in agreement with those presented from papillary muscle experiments. However, Brutsaert [2] reported 5-10 times larger values. This large difference may be caused by the manner of extrapolation to zero shortening velocity. In a hyperbolic extrapolation to $V_{\mathrm{CE}}=0$, the intercept on the force axis will be found with a high degree of uncertainty. Also high values found by Forman et al. [12] were obtained from tetanized heart muscle in which activation was influenced by caffein and high $\left[\mathrm{Ca}^{2+}\right]$. 
It is concluded that the technique used in this study enables the assessment of force-velocity relations which are in quantitative agreement with findings in heart muscle preparations. For this, the use of a relatively simple model of the ventricle suffices.

Acknowledgement. The authors wish to thank Prof. Dr. Ir. J. J. Denier van der Gon and Dr. a. Crowe for their critical remarks.

The investigations were supported (in part) by the Foundation of Medical Research, FUNGO, which is subsidized by the Netherlands Organization for Advancement of Pure Research (Z.W.O.).

\section{References}

1. Beneken, J.E.W., DeWit, B.: A physical approach to hemodynamic aspects of the human cardiovascular system. In: Physical bases of circulatory transport; regulation and exchange; $\mathrm{T}$. B. Reeve and A. C. Guyton (eds.), pp. 1-45. Philadelphia: Saunders 1967

2. Brutsaert, D. L., Parmley, W. W., Sonnenblick, E. H.: Effects of various inotropic interventions on the dynamic properties of the contractile elements in heart muscle of the cat. Circ. Res. 27, $513-522(1970)$

3. Brutsaert, D. L., Sonnenblick, E. H.: Force-velocity-length-time relations of the contractile elements in heart muscle of the cat. Circ. Res. 24, 137- 149 (1969)

4. Brutsaert, D. L., Sonnenblick, E. H.: Nature of the force-velocity relation in heart muscle. Cardiovasc. Res. Suppl. I, 18-33 (1971)

5. Burns, J. W., Covell, J. W., Myers, R., Ross, J., Jr.: A comparison of directly measured left ventricular wall stress and stress calculated from geometric reference figures. Circ. Res. 28, $611-621(1971)$

6. Burns, J. W., Covell, J. W., Ross, J. Jr. : Mechanics of isotonic left ventricular contractions. Am. J. Physiol, 224, 725-732 (1973)

7. Cosyns, J., Gutierrez-Miranda, M., Reyns, Ph., Charlier, A. A., Lavenne, F.: Superiority of developed over total pressure for heart contractility indices in dogs. Pflügers Arch. 362, 165-171 (1976)

8. Edman, K. A. P., Mattiazzi, A., Nilsson, E.: The influence of temperature on the force-velocity relationship in rabbit papillary muscle. Acta Physiol. Scand. 90, 750-756 (1974)

9. Edman, K. A. P., Nilsson, E.: The mechanical parameters of myocardial contraction studied at a constant length of the contractile element. Acta Physiol. Scand. 72, 205-219 (1968)

10. Edman, K. A. P., Nilsson, E.: The dynamics of the inotropic change produced by altered pacing of rabbit papillary muscle. Acta Physiol. Scand. 76, 236-247 (1969)

11. Edman, K. A. P., Nilsson, E.: Relationships between force and velocity of shortening in rabbit papillary muscle. Acta Physiol. Scand. 85, 488-500 (1972)

12. Forman, R., Ford, L. E., Sonnenblick, E. H.: Effect of muscle length on the force-velocity relationship of tetanized cardiac muscle. Circ. Res. 31, 195-206 (1972)
13. Gibbs, C. L.: Cardiac energetics. Physiol. Rev. 58, 174-254 (1978)

14. Grossman, W., Haynes, F., Paraskos, J. A., Saltz, S., Dalen, J. E., Dexter, L.: Alterations in preload and myocardial mechanics in the dog and in man. Circ. Res. 31, 83-94 (1972)

15. Hill, A. V.: First and last experiments in muscle mechanics. Cambridge: University Press 1970

16. Huxley, A. F.: Muscular contraction. J. Physiol. (Lond.) 243, 1 43 (1974)

17. Joseph, D. S., Huntsman, L. L.: Force-velocity relations in cardiac muscle. Biophys. J. 21, 55a (1978)

18. Parmley, W. W., Yeatman, L. A., Sonnenblick, E. H.: Differences between isotonic and isometric force-velocity relations in cardiac and skeletal muscle. Am. J. Physiol. 219, 546- 550 (1970)

19. Nejad, N. S., Klein, M. D., Mirsky, I., Lown, B.: Assessment of myocardial contractility from ventricular pressure recordings. 1 Cardiovasc. Res. 5, 15-23 (1971)

20. Nieuwenhuijs, J. H. M.: Kontraktiliteit van de linker ventrikel. Thesis, Utrecht 1976

21. Nilsson, E.: Influence of muscle length on the mechanical parameters of myocardial contraction. Acta Physiol. Scand. 85, $1-23$ (1972)

22. Noble, M. I. M., Bowen, T. E., Hefner, L. L.: Force-velocity relationship of cat cardiac muscle, studied by isotonic and quickrelease techniques. Circ. Res. 24, 821-833 (1969)

23. Schiereck, P., Boom, H. B. K.: Left ventricular active stiffness: Dependency on time and inotropic state. Pflügers Arch, 374, $135-143(1978)$

24. Sonnenblick, E. H.: Implications of muscle mechanics in the heart. Fed. Proc. 21, 975-990 (1962)

25. Sonnenblick, E. M.: Force-velocity relations in mammalian heart muscle. Am. J. Physiol. 202, 931 -939 (1962)

26. Sonnenblick, E. H.: Series elastic and contractile elements in heart muscle: changes in muscle length. Am. J. Physiol. 207, 1330-1338 (1964)

27. Suga, H., Sagawa, K.: Mathematical interrelationship between instantaneous ventricular pressure-volume ratio and myocardial force-velocity relation. 1. 2. Ann. Biomed. Eng. 1, 160-181 (1972)

28. Ter Keurs, H. E. D. J., Bloot, R., Rijnsburger, W. H.,Nagelsmit, M. J.: The influence of sarcomere length on tension development in rat heart muscle. Biophys. J. 21, 86a (1978)

29. Weber, K. T., Janicki, J. S.: Instantaneous force-velocity-length relations in isolated dog heart. Am. J. Physiol. 232, H241 - H249 (1977)

30. Yeatman, L. A., Parmley, W. W., Urschel, C. W., Sonnenblick, E. H.: Dynamics of contractile elements in isometric contractions of cardiac muscle. Am. J. Physiol. 220, 534-542 (1971)

Received July 16, 1978 